\title{
REVISIONES
}

\section{La exposición en los museos de sitio como herramienta de sensibilización al patrimonio arqueológico}

\author{
Site museums exhibition as a tool to raise awareness of archaeological heritage
}

\author{
Anik Meunier, ${ }^{a}$ Estelle Poirier-Vannier ${ }^{b}$ \\ ${ }^{a}$ Université du Québec à Montréal (UQAM) \\ Correo electrónico: meunier.anik@uqam.ca

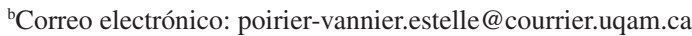

\section{RESUMEN}

Los sitios arqueológicos, testigos materiales del tiempo y de las culturas del pasado, son portadores de informaciones históricas únicas y tienen un inestimable valor simbólico y científico. A pesar de que numerosos sitios arqueológicos son conocidos y documentados en América latina, muchos de ellos han sido destruidos o saqueados debido a los pillajes. El museo de sitio arqueológico contextualiza los objetos y desempeña un papel esencial en su salvaguardia y conservación garantizando la integridad de los bienes culturales, tangibles e intangibles. ¿Por lo tanto, cómo puede la exposición del museo de sitio sensibilizar a la población local y a los visitantes sobre la importancia de la conservación del patrimonio arqueológico? A fin de responder a esta cuestión, estudiamos diferentes registros de mediación de la arqueología en tres exposiciones de museos de sitio: Chan Chan (Peru), Huacas de Moche (Peru) et Templo Mayor (Mexique).

Palabras clave: arqueología, educación, mediación, museografía, conservación.

\section{ABSTRACT}

Archaeological sites, material witnesses of the past, bear unique historical information and have an inestimable symbolic and scientific value. While many archaeological sites are known and documented in Latin America, many of them have been destroyed during looting. The archaeological site museum contextualizes objects and plays an important role in safeguarding and preserving by ensuring the integrity of cultural, tangible and intangible assets. Thus, the following question arises: How is the site museum likely to make the local population and visitors aware of the importance of archaeological heritage conservation? In order to answer this question, we have studied archaeology mediation registers in three museums: Chan Chan (Perou), Huacas de Moche (Perou) and Templo Mayor (Mexico).

Keywords: archaeology, education, mediation, museography, preservation. 


\section{INTRODUCCIÓN}

El interés por los emplazamientos arqueológicos en América Latina se remonta a la Conquista española en el siglo XVI. En su búsqueda de las misteriosas ciudades de oro, los españoles exploraron, saquearon y destruyeron numerosos sitios arqueológicos (Bondil, 2013; Migeon, 1997). Durante el siglo XIX, el comercio pujante de estos objetos en América y Europa, así como el interés por el coleccionismo, empujaron a algunos habitantes a buscar y hacer pillajes en las tumbas de sus antepasados (Pardo Grau, 2013). El tráfico de dichos objetos les proporcionaba una fuente de ingresos. A principios del siglo XIX, las autoridades intentaron frenar este fenómeno creando las instituciones museológicas nacionales con la finalidad de proteger el patrimonio histórico y arqueológico (PoirierVannier, 2016). No obstante, a pesar de estos esfuerzos, países como México y Perú siguen apareciendo en la lista roja de los bienes culturales en peligro del ICOM (2009) ${ }^{1}$. Esta lista ha sido establecida bajo la óptica de luchar contra el pillaje y la destrucción de los sitios arqueológicos y el tráfico ilícito de bienes culturales². El objetivo principal de la misma es la sensibilización de la opinión pública y la promoción de la cooperación internacional en la protección del patrimonio cultural.

A fin de proteger el patrimonio y de contrarrestar el saqueo de los sitios arqueológicos, diversos países han emprendido acciones educativas y de sensibilización implicando a la comunidad local. En numerosos países emergentes, la arqueología está en el corazón de proyectos de valorización turística. Los ingresos generados en el marco de estas actividades permiten financiar las excavaciones, la investigación y la valorización del patrimonio arqueológico. En ciertos casos, estas actividades turísticas pueden incluso estimular el desarrollo y la economía de una región. Asimismo, la puesta en valor del emplazamiento arqueológico, contribuye a la educación cultural de las comunidades locales, el fortalecimiento de una identidad regional y nacional, así como a reforzar el sentimiento de pertenencia y responsabilidad respecto del patrimonio arqueológico e histórico. En este contexto, nos cuestionamos sobre el papel del museo del sitio arqueológico, respecto a la educación del público en la preservación del patrimonio. Entre las diferentes iniciativas realizadas en este sentido, hay una en particular que consiste en organizar y desarrollar un proyecto de comunicación cultural con y para las comunidades locales. Dicho proyecto, que se muestra e implanta en el mismo museo, propone exposiciones que son una de las manifestaciones más frecuentes de la voluntad de comunicar mensajes de sensibilización sobre la conservación y la salvaguardia de los bienes culturales patrimoniales. Más concretamente, ¿cómo sensibiliza la exposición del museo de sitio a la población local y a los visitantes sobre la importancia de la conservación del patrimonio arqueológico?

A fin de responder a esta cuestión, que representa un importante desafío en la conservación de la integridad y el respeto de la perpetuidad de los sitios arqueológicos, estudiamos según un enfoque de ciencias de la educación y de la museología, los diferentes registros de mediación de la arqueología en tres exposiciones de museos de sitio, de los

\footnotetext{
Las listas Rojas del ICOM catalogan para zonas particularmente vulnerables del mundo, las categorías de objetos arqueológicos o de obras de arte en peligro, con el fin de impedir su venta y su exportación ilegal. Recuperado de http:// icom.museum/programmes/lutte-contre-le-trafic-illicite/listes-rouges/L/2/.

2 Entendemos el término bien cultural en el mismo sentido que patrimonio cultural, y en el texto presente el uno o el otro de los términos puede sustituírsele al otro.
} 
cuales dos se sitúan en Perú (Chan Chan y Huacas de Moche) y uno en México (Templo Mayor). Los sitios de Chan Chan y de Huacas de Moche se ubican en la región de La Libertad, en la costa norte de Perú. El Museo de sitio de Chan Chan fue inaugurado en 1990, mientras que el Museo de sitio de Huacas de Moche se desarrolló a partir del año 2010. Nuestro tercer caso de estudio es el Templo Mayor, ubicado en el centro de la ciudad de México, abierto en 1987. Una estancia de investigación nos permitió proceder a la recolección de datos directamente en el sitio de estudio.

Realizamos una serie de observaciones repetitivas en el sitio arqueológico y en el museo de sitio de Chan Chan y de Huacas de Moche, en Perú, en septiembre y octubre de 2014. Las observaciones del sitio arqueológico del Templo Mayor y de su museo de sitio en México han sido efectuadas en febrero de 2017. Una matriz de observaciones ha sido realizada a partir de los escritos de Jean Davallon (1992), Susan Pearce (1990), Claire Merleau-Ponty y Jean-Jacques Ezrati (2006), J. Desjardins y Daniel Jacobi (1992), Anik Meunier (2011), Jacques Hainard (2000, 2007) y Serge Chaumier (2002). La matriz era simplemente un punto de partida para nuestras observaciones, y ha sido revisada y modificada durante el transcurso de nuestro estudio sobre el terreno, según los diferentes elementos emergentes de nuestras observaciones. Las observaciones no participativas pretendían dar cuenta de las modalidades de mediación de la arqueología en el seno de los recorridos de interpretación in situ y de las exposiciones. Igualmente se realizaron entrevistas semi-estructuradas con profesionales de museos y de la arqueología con el fin de comprender mejor las modalidades y los registros de mediación, la especificidad de los objetos expuestos y los retos con los que se encuentra la mediación de la arqueología en América Latina.

\section{LA COMUNICACIÓN DENTRO DEL MUSEO DE SITIO ARQUEOLÓGICO}

El principal papel del museo de sitio consiste en salvaguardar y conservar los bienes culturales, tangibles e intangibles, in situ y velar por su integridad (ICOM, 1982). De esta forma, los numerosos museos de sitio nacieron de una voluntad de sensibilizar al público en el patrimonio arqueológico. Dentro del museo se desarrolla una herramienta de comunicación con una fuerte voluntad de sensibilización, tanto de la población local como de los turistas: la exposición. La exposición, considerada como productora de conocimientos, es parte de un sistema de comunicación destinado a facilitar la apropiación de los mismos. Bajo esta perspectiva, nos interesamos en destacar las modalidades y los dispositivos que son utilizados en las exposiciones de los museos de sitio, para presentar contenidos sobre la arqueología en el contexto latinoamericano. Nuestro análisis se fundamenta en una serie de observaciones y en el estudio del discurso de los profesionales encuestados. El enfoque predilecto es resueltamente inductivo. Este enfoque permite poner de relieve las diferentes modalidades e inferir los prejuicios comunicativos privilegiados en los tres sitios estudiados.

El objetivo fundamental de la exposición en los museos de sitio es la comunicación para instruir y sensibilizar al público, al pretender transmitir conocimientos específicos sobre temas concretos. La intención de la exposición en los museos de sitio es, ante todo, enseñar y aclarar. Su objetivo principal no es divertir, sino comunicar ciertas informaciones percibidas como esenciales a la comprensión de contenidos científicos por parte de los 
visitantes. Además, la exposición presentada en los museos de sitios arqueológicos consiste en comunicar contenidos directamente relacionados con los mensajes a transmitir, y con la importancia de proteger y salvaguardar el patrimonio arqueológico in situ.

\section{EL CONTEXTO PERUANO DE LOS SITIOS ESTUDIADOS}

Los dos primeros casos estudiados, Chan Chan y Huacas de Moche, se sitúan al exterior del corredor turístico tradicional de Perú, inscribiéndose en un contexto particular. De hecho, la costa norte de Perú rebosa de sitios arqueológicos prehispánicos, pero se encuentra desfavorecida con relación a la región centro-sur donde se encuentran numerosos vestigios inca, entre ellos los de Cuzco y de Machu Picchu. La región del centro sur recibe la mayoría de las subvenciones debido a la fuerte afluencia del turismo. La costa norte, por su parte, no goza de tanta infraestructura turística y no llama tanto la atención internacional. En este contexto, los museos de la costa norte peruana se desarrollaron más tarde que los de otras regiones de Perú.

\subsection{EL MUSEO DE CHAN CHAN}

El edificio del Museo construido en hormigón está decorado con un friso, la ornamentación está inspirada en los ornamentos en forma de pelícanos de los muros de la ciudad de Chan Chan. Se accede al edificio mediante una rampa que invoca también la arquitectura de la ciudad. La exposición del Museo de Chan Chan propone un recorrido cuyo objetivo es informar a los visitantes sobre la historia del sitio como capital política, administrativa y religiosa de la sociedad chimú ${ }^{3}$. En la primera sala (ill. 1), el recorrido de la exposición está estructurado de manera cronológica con el fin de resaltar el desarrollo de las primeras civilizaciones (11 000 a. C.) hasta el de Chimús (1000 a 1470 a. C.). La configuración del mismo responde al modelo dinámico propuesto por Pearce (1990), donde se presenta una progresión de los acontecimientos históricos. Según la autora, la configuración de la exposición cuyo trayecto es lineal, anima a una lectura continua y un trayecto cronológico. Las salas de exposiciones dispuestas alrededor de un largo corredor (ill. 2) incitan al visitante, quien sigue una secuencia preestablecida y descubre un mensaje predeterminado. En la segunda sala, el enfoque funcional (ill.3), en el sentido de Pearce (1990), da cuenta de la utilización de los objetos expuestos y creados por la cultura chimú. Por ejemplo, una diversidad de objetos está reagrupada en un escaparate para explicar ciertas prácticas agrícolas permitiendo comprender mejor las herramientas, las técnicas y los materiales utilizados. El enfoque de exposición del Museo de Chan Chan se inscribe en una museología de idea en la cual los objetos están puestos al servicio de un mensaje (Davallon, 1992). Es la reagrupación de objetos la que le confiere sentido a la exposición, conectando al visitante con el contenido. Según Davallon (1992), privilegiando la museología de idea, el diseñador de la exposición pretende concebir una herramienta de comunicación que favorece la transmisión de informaciones y la apropiación de los objetos por el visitante. Con este fin, en Chan Chan el objeto está presentado como testimonio de la historia. En este contexto, Chaumier

Las salas del Museo de Chan Chan se presentan así: Sala Orígenes, Sala Cultura, Sala Referencias, Sala Recinto y Sala Tradición. 
(2002) sostiene que el artefacto tiene un significado que va más allá de este, y que debe entonces estar acompañado por un discurso que le permita ser interpretado y comprendido por los visitantes. En la primera sala, por ejemplo, el objeto sirve para testimoniar la historia narrada en cuanto al desarrollo de las civilizaciones del Perú. Varios registros de sentidos o registros semióticos están involucrados. Las fotos se utilizan sobre todo como documento para apoyar esta narración. La exposición presenta un número limitado de objetos en escaparate ( $\mathrm{n}=$ aproximadamente 50), lo que confirma la utilización del artefacto en calidad de testigo material de la historia. De hecho, en contraste con el bajo número de objetos, se encuentran muchos paneles didácticos $(n=51)$. Algunos representan mapas $(n=8)$, otros fotos o gráficos $(n=24)$. Contamos también con dioramas $(n=7)$ y modelos $(n=7)$. En otras palabras, la exposición se articula alrededor del texto y de la narración y no alrededor de los objetos. Los creadores consideraron oportuno emplear registros que difieran de la presentación simple de los objetos, con el fin de apoyar sus declaraciones vinculadas a los mensajes de salvaguardia y de conservación del patrimonio arqueológico.

\section{Presentación de la disciplina arqueológica}

En el marco de una exposición arqueológica, las herramientas de interpretación desempeñan un papel importante, ya que el fragmento de un objeto que proviene de una civilización del pasado a menudo tiene poco sentido para los visitantes no expertos. En esta óptica, los textos de la exposición son importantes para volver a contextualizar el objeto y explicar su función. En este sentido, Desjardins y Jacobi (1992) destacaron dos funciones principales ligadas al cartel. En primer lugar, el cartel serviría para identificar, es decir, para nombrar y para designar el objeto. Con el tiempo, el cartel también habría desarrollado un papel de mediación: interviene entre el objeto y la acción de apropiación del saber por parte del visitante (Desjardins \& Jacobi, 1992). Por otra parte, estos autores afirman que varios estudios (Bitgood, et al., 1986; Borun \& Miller, 1980; Hodges, 1978) han mostrado la relación entre el tamaño del texto y su atractivo para los visitantes. Cuanto más limitada es la cantidad de palabras, más grande es el atractivo y los visitantes son más propensos a retener las informaciones que les son presentadas.

En Chan Chan, las etiquetas no son uniformes, llegando incluso a estar a veces ausentes. Pudimos observar que no todas fueron traducidas al inglés y que algunas indicaban el periodo histórico, mientras que otras fijaban el nombre de la civilización. Ninguna menciona la procedencia del objeto. En otros términos, el hecho de abastecer de la información incompleta sobre el objeto o de privarlo de su cartel, tiene ciertamente un impacto sobre la recepción de las informaciones por parte del visitante, y más aún sobre la apropiación del saber sobre la arqueología. El objeto está despojado de su sentido y de su significado. Los textos de sección (entre 100 y 200 palabras) y aquellos que se encuentran en los escaparates (entre 75 y 150 palabras) proponen una contextualización social, política y económica; geográfica y cronológica en inglés y en español. El vocabulario técnico y los métodos utilizados en arqueología han sido ocultados en los textos. No obstante, aunque la presentación de la arqueología en el Museo de Chan Chan es didáctica, ninguna referencia está hecha a los métodos utilizados en las excavaciones ni al desarrollo de su interpretación o a los daños que resultan del vandalismo.

Shanks y Tilley (1992) destacan particularmente la importancia de exponer los elementos ligados a la construcción del mensaje para que la arqueología sea presentada 
como un trabajo en curso. De este hecho, se observa una fuerte autoridad del discurso de los creadores conceptuales de la exposición sobre la historia de las civilizaciones, más específicamente sobre el desarrollo prehispánico de la región y la evolución de los primeros artefactos de piedra a la cerámica de las grandes civilizaciones. Este enfoque preconizado por medio de la exposición fomenta una lectura del arte de las diferentes civilizaciones que son presentadas, proponiendo así una cierta jerarquía de estilos, presuponiendo que las producciones más recientes son más logradas. En otras palabras, la exposición del Museo de sitio de Chan Chan presenta un discurso que sostiene la narrativa histórica oficial. El visitante tiene pocos dispositivos conceptuales e información para desarrollar sus propias reflexiones.

Por otra parte, la exposición de Chan Chan utiliza un enfoque muy didáctico para presentar contenidos sobre la arqueología. De hecho, la diversidad de los públicos implica la necesidad de contextualización de la arqueología y esto, desde un punto de vista social, económico y político. Los públicos no especializados suelen poseer muy pocas bases sobre la arqueología y requieren herramientas para ayudarles a desarrollar su reflexión. Las herramientas de interpretación en la exposición tales como los mapas, los modelos, las fotos, los planes, los dioramas y los multimedia favorecen no solamente un modo de aprendizaje cognitivo, sino sobre todo un modo de aprendizaje que suscita la emoción. En efecto, ciertas personas desean comprender el funcionamiento de un sistema o de un objeto, otros prefieren aprender a partir de hechos, de estadísticas, de una historia o de una noción científica, mientras que otras privilegian los contenidos que se refieren a los valores sociales, al modo de vida, al sujeto de actualidad, a las actitudes o a los comportamientos con el fin de ser estimulados en sus aprendizajes. Un equilibrio entre los tres modos de aprendizaje (cognitivo, emotivo y sensitivo) permite llegar mejor al visitante. Por consiguiente, observamos que la exposición del Museo de Chan Chan contenía pocos textos, pero muchas herramientas de interpretación (imágenes, modelos, tecnologías multimedia y dioramas). Los modelos ilustran la forma y la función que tenían los palacios y otros sectores de la ciudad, y son susceptibles de mejorar la comprensión del visitante. También ofrecen una perspectiva sobre el crecimiento y el desarrollo del palacio. En cuanto a esta, la reconstitución histórica (ill. 4) permite asociar los objetos a los personajes y a su medio original. No obstante, este método no favorece siempre la reflexión del visitante. A menudo reproduce una visión de este período conforme con la adquirida previamente. La exposición sobre Chan Chan comprende también un conjunto de tecnologías multimedia que favorecen una puesta en escena del objeto arqueológico. Haciéndole más susceptible de ofrecer una comprensión más dinámica de la civilización chimú y de la ciudad. Sin embargo, la exposición creada y realizada en 1990 jamás ha sido actualizada y las tecnologías multimedia de la época son ahora obsoletas. La obsolescencia de los medios tecnológicos empleados en el Museo puede inducir una cierta indiferencia por parte del visitante.

La elección del decorado, la iluminación y los dispositivos tecnológicos utilizados para la valorización del objeto arqueológico influyen en la percepción de los visitantes y, por consiguiente, en la apropiación de los contenidos. En efecto, la escenografía permite contextualizar los objetos arqueológicos aislados de su contexto de origen y favorecer la transmisión de los contenidos. A este respecto, Merleau-Ponty y Ezrati (2006) destacan que los etnólogos favorecen las informaciones visuales y textuales con el fin de apreciar y comprender mejor los objetos extraños para nuestra cultura, facilitando la aculturación. 
Con este fin, los autores destacan tres formas de situación espacial: el espacio minimalista, el espacio decorado y la escenografía teatral (Merleau-Ponty \& Ezrati, 2006). El Museo de Chan Chan opta por una postura en espacio con decorado para presentar los objetos de excavaciones arqueológicas. El decorado pretende facilitar el contacto entre la obra y el visitante. No obstante, el Museo de Chan Chan utiliza medios que se puede cualificar de discretos (Merleau-Ponty \& Ezrati, 2006). Dentro de las salas de exposiciones predomina el color amarillo-beige en paredes y el rojo en los suelos. Recuerdan la cerámica chimú. En cuanto a la iluminación de las salas, esta es más bien uniforme. El museo recurrió, no obstante, a la reconstitución histórica para poner en contexto el artefacto. Sin embargo, esta técnica apela a la experiencia y a las representaciones, lo que le hace accesible a un público amplio (Merleau-Ponty \& Ezrati, 2006).

\subsection{EL MUSEO DE HUACAS DE MOCHE}

El Museo de Huacas de Moche propone un recorrido temático para descubrir la cultura moche. Este contiene tres salas y la exposición está orientada sobre nueve temas ${ }^{4}$. El recorrido circular (ill.5-6) permite al público desplazarse alrededor de las instalaciones con toda libertad. Los creadores conceptuales de la exposición no se sitúan como únicos poseedores del saber y no imponen su punto de vista ni su interpretación del pasado. El saber es, en cambio, presentado como un proceso en desarrollo donde un campo de significados múltiples puede tomar forma. Como tal, Falk y Dierking (2000) resaltan la importancia de la interacción y la participación del visitante en su visita de una exposición. Las decisiones tomadas por el propio visitante; el control de su trayecto de visita es susceptible de favorecer su aprendizaje. Según estos autores, el visitante debe estar comprometido con la experiencia de visita y basarse en un enfoque que lo anime a tomar decisiones y acciones concretas que tienen una incidencia sobre su trayecto y su reflexión. A este respecto, Pearce (1990) afirma que un trayecto de visita que presenta un gran número de posibilidades de interpretación puede generar diversas respuestas a las cuestiones planteadas. En el Museo de Huacas de Moche, la sala de exposiciones principal se organiza alrededor de un islote central, a partir del cual emergen las mesas de exhibición. Este módulo central proyecta una animación gráfica y audiovisual que introduce al visitante a cada uno de los temas tratados en las nueve secciones. Tras la proyección, el visitante es sutilmente dirigido hacia los escaparates mesas que contienen las piezas más representativas de cada sección, y a continuación, hacia los otros soportes y escaparates murales. El módulo central permite especialmente crear una división de la sala en diferentes secciones. El discurso de la exposición se orienta principalmente alrededor de la cultura intangible. Igual que el Museo de Chan Chan, este dispositivo de mediación corresponde al concepto de museología de idea adelantado por Davallon (1992).

Desde la creación del Convenio de la salvaguardia del patrimonio cultural inmaterial en 2003 por la UNESCO, las instituciones museísticas otorgan un especial interés a la difusión de la cultura intangible en sus exposiciones. En este sentido, el enfoque de exposición escogido por el museo de Huacas de Moche no se centra únicamente en las

Los nueve temas que pretenden comprender mejor la cultura y el mundo moche son los siguientes: Los Moches, El Complejo de Moche, Los señores sacerdotes, El culto a Ai Apaec, El poder del Templo viejo, Las ceremonias, Los sacrificios, La vida en la ciudad y La pieza del Mes. 
características formales del objeto y de su función, sino sobre todo en su significado para la sociedad moche. Por otra parte, el objeto pierde su función de origen para adoptar un nuevo sentido cuando está reagrupado con otros objetos. Por ejemplo, objetos con funciones distintas, pero con patrones similares pueden estar asociados para representar un tema particular, tal como naturaleza, los rituales (ill. 7) o la caza. El objeto es utilizado como pretexto para crear nuevos significados y apoyar una narrativa construida por la institución (Chaumier, 2002).

\section{Presentación de la disciplina arqueológica}

El Museo de Huacas de Moche adopta una combinación de enfoques para presentar la arqueología. Además del enfoque temático, la exposición de este museo presenta diversos elementos del enfoque funcional, ya que se centra en explicar la función de estos objetos y las técnicas artesanales de la civilización moche (Pearce, 1990). El museo expone también los métodos de datación y de excavación utilizados para apoyar sus explicaciones. También, se presta mucha atención a las características estilísticas del objeto y su iconografía. Las representaciones iconográficas sobre la cerámica moche permiten informar al público sobre las creencias y actividades practicadas por los Moches. Asimismo, observamos que el proceso de adquisición del saber arqueológico ha sido transmitido al visitante. Esta elección permite evitar la proposición de un discurso cuajado del pasado (Shanks \& Tilley, 1990). El visitante está estimulado a reflexionar sobre el proceso de interpretación y a crear conexiones para formar su propia idea. Por ejemplo, uno de los escaparates de la sala de los mausoleos presenta fotos y dibujos gráficos de las tumbas (ill. 8) y explica que los huesos del esqueleto no fueron articulados juntos en el momento del descubrimiento. Los arqueólogos creen que el cuerpo habría sido desplazado en la época de los Moche, de su primer lugar de sepultura hacia una nueva tumba más reciente (última fase constructiva de Huaca de la Luna), ya que probablemente se trataba de un jefe de las primeras fases de la civilización moche que debía ser enterrado de nuevo. El hecho de descubrir ofrendas de cerámica de un estilo que corresponde a una de las fases anteriores de la construcción del templo apoya esta hipótesis formulada por los arqueólogos.

En el Museo de Huacas de Moche, la presentación del objeto arqueológico adopta un enfoque didáctico para que los contenidos complejos sean accesibles a todos los públicos. La narración de la exposición preconiza el cuento. A este respecto las investigaciones, incluyendo aquellas de McManus (1992), destacan la importancia de concebir textos adaptados al gran público con el fin de favorecer el diálogo entre el autor (creador conceptual) y el lector (visitante). En efecto, estas afirman que el texto de los carteles es a menudo leído en voz alta, compartido y discutido dentro del grupo de visitantes. Según la investigadora, cuando los visitantes leen los textos explicativos, tienen la impresión de que alguien les habla. Algunos llegan a confirmar las informaciones, plantear cuestiones, emitir observaciones o responder a ciertos comentarios del texto explicativo (McManus, 1992). En el Museo de Huacas de Moche contamos 65 paneles didácticos escritos en inglés y en español. La mayoría de los carteles son descriptivos y explicativos. Informan sobre la procedencia y la función del objeto, además de describir el estilo, la ornamentación y la forma. Los textos de sección (250 a 300 palabras) y los textos de escaparate (100 palabras) disponen de mapas, fotos y dibujos gráficos como material de apoyo que indican la procedencia y la función de los objetos valorizados. El enfoque por temáticas, que es 
adoptado por los creadores conceptuales del Museo, representa los diferentes contextos de origen del objeto. Por otra parte, ciertas mesas escaparates y escaparates murales contienen un grafismo contextual de las piezas en exposición. En la sala de los mausoleos, el contexto del artefacto ha sido respetado con la ayuda de una foto de la tumba expuesta (ill. 8) en cada uno de los escaparates, la que permite una visualización global para el visitante.

Los museólogos apostaron también por numerosas tecnologías para favorecer una mejor comprensión de los contenidos expuestos. De hecho, la técnica de animación es ideal para recrear procesos del pasado actualizados por la arqueología. La reconstitución de los vestigios de construcciones prehispánicas sería más compleja de representar a través de elementos estáticos tales como fotos o textos. Así, cuando el visitante entra al museo, es atraído hacia una proyección en el cubo central de la sala. Cada una de las caras laterales del cubo presenta una animación en la que se explica, entre otras cosas, la construcción y el desarrollo de Huaca de la Luna, los combates y los sacrificios moches. Se trata de la recreación de una maqueta virtual del complejo, donde cada uno de los elementos está fotografiado individualmente, y son unidos a continuación para proporcionar la sensación de que están en movimiento en una animación stop motion. Por lo tanto, la proyección introduce al visitante en cada una de las temáticas presentadas en las diferentes secciones de la exposición. Una variedad de apoyos de interpretación es utilizada por el museo para ilustrar el contexto sociopolítico y socioeconómico de la sociedad moche, tales como textos, fotos y gráficos. Un mapa geográfico de Perú, otro de las zonas de ocupación, así como uno del sitio y los talleres proporcionan una mejor visualización. Además, la información ha estado dividida en pequeños párrafos al lado de los objetos, con el fin de proporcionar información especializada sobre su procedencia. Asimismo, las palabras clave de los textos están subrayadas en color con la finalidad de destacarlas. Esto permite al visitante hacer una lectura selectiva de la información.

En cuanto a la escenografía, el Museo de Huacas de Moche ha optado por la construcción de un edificio que se remite al contexto original de los objetos, especialmente por su forma de pirámide truncada y su fachada escalonada. El pozo de luz de la sala principal también está diseñado en forma piramidal. El centro comunitario sigue un modelo inspirado en las técnicas y materiales tradicionales utilizados por los Moches tales como el adobe, el barro y la caña. Dentro del museo, la elección ha sido orientada hacia una situación espacial con decorado (Merleau-Ponty \& Ezrati, 2006). Al igual que Chan Chan, los medios utilizados para situar espacialmente los objetos son más bien discretos. El color de las paredes y de los expositores ha sido escogido de acuerdo con la estética de los objetos. El color marrón crema recuerda a la tierra, a las construcciones y a la cerámica moche. La evocación se realiza igualmente a través del uso de expositores escalonados (ill. 5) y la disposición de los objetos (ill. 9) en la arena en referencia a la arqueología. Merleau-Ponty y Ezrati (2006) explican que el decorado (la vegetación, los tejidos, el mobiliario, las fotografías y las pinturas) son utilizados para evocar un contexto o un ambiente que permite acercar al visitante al tema de la exposición (Merleau-Ponty \& Ezrati, 2006). Por ejemplo, las salas de exposiciones de Huacas de Moche, más particularmente las de los mausoleos, están sumergidas en la semioscuridad. El color negro de los paneles de los escaparates murales contribuye al ambiente, reforzando la atmósfera dramática de la sala. El camino por el pasillo que une las salas está acompañado por una música inspirada en instrumentos tradicionales. Estos dispositivos son utilizados para crear la atmósfera, restituir el contexto y favorecer la recepción o el encuentro entre el visitante y el objeto arqueológico. 


\subsection{EL MUSEO DEL TEMPLO MAYOR}

El Museo del Templo Mayor se encuentra en el centro histórico de México, cerca de la zona arqueológica. El descubrimiento accidental del monolito de la diosa lunar Coyolxauhqui en 1978, durante los trabajos de excavación en la Plaza de armas (Zócalo), dio origen al proyecto de investigación del Templo Mayor. La iniciativa del Museo de sitio nació en respuesta a la primera temporada de excavaciones arqueológicas (1978-1982) que había permitido recuperar 7000 objetos en el sitio. La institución abrió sus puertas cinco años más tarde (1987).

La exposición del Templo Mayor pretende hacer descubrir la cultura azteca a través de ocho temáticas ${ }^{5}$. La orientación del recorrido de la visita se hace a través de tabiques amovibles que delimitan los sectores, así como por las escaleras que guían el paso del visitante de una sala a otra. El trayecto obligado (ill. 10) del visitante le incita a seguir una secuencia predeterminada. La división de la exposición (norte/sur) está inspirada en el Templo Mayor en sí mismo. La parte sur, dedicada al dios solar Huitzilopochtli, se refiere a las guerras y tributos, mientras que la parte norte, dedicada al dios de la lluvia Tláloc, está relacionada con la fertilidad de la tierra. El enfoque temático del Museo permite destacar el patrimonio intangible de la cultura azteca. En esta línea, un museólogo con quien se realizó una entrevista sostiene que la descolonización de los museos llevó a estas instituciones a privilegiar un enfoque donde los objetos arqueológicos procedentes de excavaciones sirven para poner al visitante en el contexto de la exposición y explicar las sociedades, en lugar de estar presentados solamente como un descubrimiento. Esto crea una continuidad entre las culturas del pasado y las del presente. Así, tanto en el Templo Mayor como en Huacas de Moche, la presentación del objeto no se hace exclusivamente a partir de las características formales del objeto y su función, sino destacando sobre todo elementos vinculados a la cultura azteca. En el caso de esta exposición, el artefacto aparece como pretexto para ilustrar un discurso (Chaumier, 2002). El dispositivo de comunicación corresponde al concepto de museología de idea avanzado por Davallon (1992).

\section{Presentación de la disciplina arqueológica}

En el Museo del Templo Mayor se presta una gran atención a la presentación de la arqueología. El Museo utilizó el enfoque funcional (Pearce, 1990) con el fin de hacer ciertos contenidos arqueológicos más claros para los visitantes. En primer lugar, una sala entera está dedicada a los orígenes de la arqueología. Esta sala presenta un panorama del desarrollo de la investigación arqueológica en México desde 1790 hasta hoy. La historia del proyecto arqueológico del Templo Mayor está aquí relatada, así como la explicación del programa de arqueología urbana. Además, una línea cronológica permite situar en el tiempo los proyectos de arqueología en México, así como sus principales contribuidores. En la sexta sala, se hace referencia a la arqueo-biología, donde se encuentran especialidades como la arqueo-botánica o la arqueo-zoología, cuyo objetivo es la identificación de especies animales o especies botánicas descubiertas sobre el sitio (ill. 11). El texto explica que estas

Los ocho temas que pretenden comprender mejor la cultura y el mundo azteca son los siguientes: Antecedentes arqueológicos, Ritual y Sacrificio, Tributo y Comercio, Huitzilopochtli, Tláloc, Flora y Fauna, Agricultura, Arqueología Histórica. 
disciplinas permiten el avance de los conocimientos sobre la relación entre el hombre y su medio ambiente natural en el pasado. Fontal (2003) se refiere a Colom (1998) en su obra, cuando afirma que la educación patrimonial integra la realidad cultural y natural. El autor señala que, desde hace poco, la dimensión de la cultura y de la naturaleza interactúan constantemente y que, a menudo, forman parte de la misma realidad patrimonial, siendo indisociables (Fontal, 2003). En la séptima sala, ciertos escaparates presentan objetos reagrupados que representan las herramientas de labranza. Un dibujo gráfico ilustra una escena de labranza como soporte. Todos los objetos están acompañados por un cartel (inglés y español) que hace referencia a la procedencia del objeto, a la fecha de su descubrimiento y a su función. Varios carteles señalan el período de construcción del templo al cual el objeto pertenece y algunos señalan el estilo del objeto, la descripción del lugar de descubrimiento, la simbología del objeto o su asociación a una cierta deidad. Asimismo, encontramos carteles que identifican la especie animal presentada en el escaparate. Además, algunos paneles interpretativos contienen fotos que ofrecen información visual sobre el lugar de procedencia del objeto. También encontramos un panel interpretativo haciendo referencia a la conservación y la restauración del monolito de la diosa Coyolxauhqui y la presencia de textos de escaparate y de sección (de 115 y 200 palabras). En resumen, en el Museo del Templo Mayor la presentación de la arqueología se hace de manera muy didáctica.

Por otro lado, muchas herramientas de ayuda a la interpretación son utilizadas para facilitar el acceso a dichos contenidos a la mayor variedad de público posible. Según Merleau-Ponty y Ezrati (2006), la exposición no sirve solamente para la adquisición de conocimientos, sino también para asistir a la interpretación, y nos lleva a una forma viva del saber. Así, los autores sostienen que la exposición ahora tiene como objetivo desarrollar la actividad afectiva, sensual e intelectual de los visitantes alrededor de las obras. Esta experiencia puede estar suscitada por la escenografía, pero sobre todo por los materiales de soporte a la visita y los mediadores (Merleau-Ponty \& Ezrati, 2006). Por ejemplo, los textos, las fotos y los gráficos permiten ilustrar el contexto sociopolítico y socioeconómico, crear un vínculo con el sitio e identificar a los animales presentados en escaparate. En cuanto a los planes, los mapas y los modelos, estos pretenden situar geográficamente los restos arquitectónicos. También observamos una reconstitución histórica del hábitat (ill. 12) y de los modos de alimentación de la sociedad azteca. Esto permite asociar los objetos de los escaparates con su entorno de origen. En la sexta sala, que se refiere a la fauna y la flora, varios animales naturalizados (ill. 11) han sido dispuestos en escaparate al lado de los esqueletos descubiertos. Esto permite una mejor asociación a la fauna y a la flora. Además, ciertas reproducciones de pinturas murales permiten visualizar los frisos de origen descubiertos en el sitio. Asimismo, algunos terminales interactivos han sido dispuestos en ciertas salas de exposición con el fin de que el visitante pueda interactuar escogiendo para profundizar los elementos observados en la sala de su preferencia.

El decorado de la exposición del Museo del Templo Mayor también ayuda a recrear el contexto del objeto y acercar al visitante al sujeto de la exposición. Según Merleau-Ponty y Ezrati (2006), las escenografías a decoración o teatrales son ideales para los públicos que van poco al museo. Para los públicos jóvenes, se tendría que privilegiar una escenografía que sea atrayente físicamente y a la vez variada (subir, descender, girar, bajar), así como interactiva (Merleau-Ponty \& Ezrati, 2006). A este respecto, el Museo del Templo Mayor parece haberse orientado hacia una puesta en escena a decoración para presentar su exposición de objetos arqueológicos. Por ejemplo, ciertas tumbas han sido reconstituidas 
con las ofrendas tal y como (ill. 13) fueron descubiertas en el sitio. También observamos que ciertos objetos habían sido depositados en la arena. Ciertos expositores escalonados hacen referencia a las diferentes capas excavadas por los arqueólogos. El Museo también incorporó numerosas reconstituciones en la exposición. En este sentido, al final de la exposición una pared decorada con 240 cráneos de piedra hace una llamada al altar Tzompantli en la zona arqueológica (ill. 14). Además, ciertos elementos de la arquitectura del sitio han sido reproducidos en la exposición, tales como frisas murales o pequeños templos (ill. 15). Por otro lado, los colores de cada una de las salas han sido escogidos de acuerdo con el tema de la sección: el color agua decora las paredes de la sección, que se refiere al dios de la lluvia, y el bosque verde ha sido seleccionado para la sala que se refiere a la fauna y la flora. En cuanto a la luz, es tamizada en todas las salas con el fin de crear un ambiente dramático.

Cuadro 1. Síntesis del estudio de los tres museos de sitios arqueológicos

\begin{tabular}{|c|c|c|c|}
\hline Características & $\begin{array}{l}\text { Museo de } \\
\text { Chan Chan }\end{array}$ & $\begin{array}{l}\text { Museo de Huacas } \\
\text { de Moche }\end{array}$ & $\begin{array}{c}\text { Museo del } \\
\text { Templo Mayor }\end{array}$ \\
\hline Recorrido & lineal cronológico & $\begin{array}{l}\text { circular } \\
\text { narrativa }\end{array}$ & $\begin{array}{l}\text { marcado } \\
\text { secuencial }\end{array}$ \\
\hline Enfoque & $\begin{array}{l}\text { cronológico } \\
\text { [funcional] }\end{array}$ & $\begin{array}{l}\text { temática } \\
\text { [funcional, estética] }\end{array}$ & $\begin{array}{l}\text { temática } \\
\text { [funcional] }\end{array}$ \\
\hline $\begin{array}{l}\text { Tipo de } \\
\text { Museología }\end{array}$ & ideas (textos y narración) & ideas & ideas \\
\hline $\begin{array}{l}\text { Papel del } \\
\text { Objeto }\end{array}$ & testimonio de la historia & $\begin{array}{l}\text { pretexto para nuevos } \\
\text { significados culturales }\end{array}$ & $\begin{array}{l}\text { pretexto para nuevos signifi- } \\
\text { cados culturales }\end{array}$ \\
\hline $\begin{array}{l}\text { Tipo de } \\
\text { Exposición }\end{array}$ & didáctica & didáctica & didáctica \\
\hline Escenografía & decorado & decorado & decorado \\
\hline $\begin{array}{l}\text { Presentación de } \\
\text { la Arqueología }\end{array}$ & Poco o nada & $\begin{array}{l}\text { Gran contextualiza- } \\
\text { ción, referencia a las } \\
\text { excavaciones y al de- } \\
\text { sarrollo de la interpre- } \\
\text { tación }\end{array}$ & $\begin{array}{l}\text { Sala entera dedicada a la pre- } \\
\text { sentación de la arqueología, } \\
\text { gran contextualización, refe- } \\
\text { rencia a la conservación y a la } \\
\text { restauración de los objetos }\end{array}$ \\
\hline
\end{tabular}

\section{CONCLUSIÓN Y SÍNTESIS}

Con la ayuda de estos tres estudios de caso intentamos responder a la siguiente cuestión: ¿cómo favorece la exposición del museo de sitio arqueológico el desarrollo de los conocimientos y la sensibilización, así como a la salvaguardia del patrimonio arqueológico in situ? Destacamos por el análisis de los diferentes sitios estudiados que los museos son reales dispositivos de comunicación. Esta última se desarrolla entre otras cosas según las limitaciones y las posibilidades del sitio mismo. Así, pudimos observar que la interpretación 
de la arquitectura precolombina plantea nuevas cuestiones y nuevas interpretaciones. Dentro del museo, la presentación es cada vez menos orientada sobre la cultura material, a favor de una orientación sobre la difusión del patrimonio intangible. Los temas relacionados con la arquitectura precolombina, el saqueo, la conservación y la restauración de los restos se tratan a menudo dentro del recorrido de visita in situ. Se repiten a menudo los vínculos entre el sitio y el museo, especialmente por la indicación de la procedencia del objeto, fotos y gráficos que ilustran el entorno de origen del objeto, la mención del proyecto, así como los métodos y fechas de las excavaciones sobre el cartel. La gran contextualización del objeto, al igual que la presentación del desarrollo de la interpretación sobre la arqueología, reflejan una voluntad de presentar esta última como una disciplina en desarrollo donde las interpretaciones múltiples pueden tomar cuerpo. Esto favorece el desarrollo de la reflexión del visitante. Además, la escenografía es cada vez más utilizada en los museos con el fin de fomentar un acercamiento entre el visitante y el objeto. Dentro de los tres museos estudiados, una presentación del espacio a decoración que evoca la arqueología permite contextualizar mejor el objeto y pretende favorecer la apropiación de los contenidos arqueológicos por los visitantes.

En resumen, analizamos ejemplos que nos permiten identificar las intenciones de comunicación de los mensajes vinculados a la sensibilización del patrimonio arqueológico, ya que los museos de sitio han sido concebidos con este fin preciso. No obstante, los análisis producidos nos incitan a matizar los mismos fundamentos de los objetivos perseguidos por los museos de sitio. En efecto, a menudo tienden a ocultar el mensaje de la importancia de la salvaguardia y de la conservación del patrimonio arqueológico y difunden de otro modo la arqueología. En los museos que estudiamos, el mensaje de salvaguardia no parece predominar en los enfoques de puesta en exposición. La arqueología no tiene un lugar preponderante en la presentación de los artefactos. El discurso de la exposición está orientado hacia la reconstrucción del desarrollo de la historia de la región o de la nación en un modo cronológico o, hacia la presentación de la cultura intangible de la sociedad estudiada. La narrativa histórica tiene como objetivo la construcción y el desarrollo de una identidad regional o nacional, o memorias colectivas. Por otro lado, el enfoque temático permite profundizar nuestros conocimientos sobre aspectos diversos vinculados a la cultura de la civilización estudiada. Esto permite una aproximación con la comunidad local específicamente, permite la creación de lazos y favorece la continuidad de la historia de los objetos que provienen del sitio. En otros términos, estas exposiciones pretenden informar al visitante sobre los descubrimientos locales y el avance de la investigación, así como la historia del sitio y de la región. Estas acciones contribuyen a sensibilizar a los visitantes y la población local al patrimonio cultural de la región para fomentar el sentimiento de pertenencia, así como el fortalecimiento de una identidad regional fuerte con el fin de reducir el saqueo de los sitios.

Después de haber inferido en los resultados de nuestras observaciones sobre los terrenos estudiados, analizamos el discurso de los creadores conceptuales y de los arqueólogos y consideramos la exposición desde su punto de vista. Las intenciones perseguidas por los profesionales de estos museos a la atención de los visitantes están claramente identificadas y descritas. No obstante ¿estas intenciones de comunicar contenidos ligados a la arqueología y a las realidades de cada uno de los sitios arqueológicos, aunque presentadas en el museo son percibidas de este modo por las diferentes categorías de visitadores que deambulan en los museos de sitios arqueológicos? Esta investigación permanece abierta. 


\section{REFERENCIAS BIBLIOGRÁFICAS}

Bondil, N. (2013). Le XXI' siècle contre le braconnage de la mémoire. De l'œuvre d'art au bien culturel: une histoire identitaire au Pérou. In V. Pimentel (Dir.), Pérou les royaumes du soleil et de la lune (p. 17-18). Montréal: Musée des beaux-arts de Montréal.

Chaumier, S. (2002). L'objet de musée (dossier thématique), 1-13.

Colom, A. J. (1998). Educación Ambiental y la Conservación del Patrimonio. En A. J. Colom, J. Sarramona, \& G. Vazquez (Eds.), Educación no formal (pp. 127-150). Barcelona: Ariel.

Davallon, J. (1992). Le musée est-il vraiment un média? Publics et Musées, Regards sur l'évolution des musées, 2, 99-123.

Desjardins, J., \& Jacobi, D. (1992). Les étiquettes dans les musées et les expositions scientifiques et techniques. Publics \& Musées, 1, 13-32.

Falk, J., \& Dierking, L. (2000). Learning from Museums: Visitor Experiences and the Making of Meaning. Walnut Creek (California): AltaMira Press.

Fontal, O. (2003). La educación patrimonial. Teoría y práctica en el aula, el museo e internet. Gijon: Ediciones Trea, S. L.

Hainard, J., \& Kaehr, R. (2000). Objets prétextes objets manipulés. Neuchâtel: Musée d'Ethnographie de Neuchâtel.

Hainard, J. (2007). L'expologie bien tempérée. Quaderns-e. Institut Català d'Antropologia, 09. Available at http://www.antropologia.cat/antiga/quaderns-e/09/Hainard.htm.

McManus, P. (1992). Attention! Les visiteurs lisent vos textes dans les musées. La Lettre de l'OCIM, 25, 11-17.

Merleau-Ponty, C., \& Ezrati, J.J. (2006). L'exposition, théorie et pratique. Paris: L'Harmattan.

Meunier, A. (2011). Les outils pédagogiques dans les musées: pour qui, pour quoi?. La Lettre de l'OCIM, 133, 5-12.

Migeon, G. (1997). Archéologie et idéologie au Mexique. Les nouvelles de l'archéologie, 67, (pp. 49-52). Paris: Éditions Errance.

Pardo Grau, C. (2013). La matérialisation du passé: bref exposé de la constitution des collections archéologiques au Pérou. In V. Pimentel (Dir.), Pérou les royaumes du soleil et de la lune (p. 34-38). Montréal: Musée des beaux-arts de Montréal.

Pearce, S. (1990). Archaeological Curatorship. London, New York: Leicester University Press.

Poirier-Vannier, E. (2013). La mise en valeur du patrimoine archéologique sur la côte nord du Pérou (Mémoire de maîtrise). Montréal: Université de Montréal.

Shanks, M., \& Tilley, C. (1992). Reconstructing Archaeology. Theory and Practice (2e éd.). New York: Routhledge. 